\title{
Pengaruh Budaya Organisasi Terhadap Kualitas Informasi Berdampak pada Individu Organisasi
}

\author{
ULLY ASFARI ${ }^{1}$, SUBADERI ${ }^{2}$, HAWWIN MARDHIANA ${ }^{3}$ \\ ${ }^{1,3}$ Sistem Informasi (Institut Teknologi Telkom Surabaya) \\ ${ }^{2}$ Teknik Informatika (Universitas Wijaya Putra) \\ Email: ully.asfari@ittelkom-sby.ac.id
}

Received 30 November 201x | Revised 30 Desember 201x | Accepted 30 Januari 201x

\begin{abstract}
ABSTRAK
Budaya organisasi mempunyai peran terhadap kualitas sebuah informasi. Tidak sedikit organisasi yang menganut budaya tradisional (bapakisme) dalam operasional kesehariannya. Bapakisme adalah istilah budaya tradisional yang didominasi oleh kekuasaan pimpinan. Hal ini menjadi menarik saat sebuah budaya mampu membentuk pola kerja suatu organisasi. Pada penelitian ini menunjukan bahwa budaya bapakisme berpengaruh terhadap dampak individual suatu organisasi. Metode penelitian yang dilakukan secara kualitatif dan kuantitatif. Hal ini dilakukan untuk mengetahui dampak budaya bapakisme di Indonesia khususnya di organisasi yang dekat dengan masyarakat. Posyandu didirikan tahun 1984 menjadi objek pendukung penelitian karena merupakan organisasi yang masih aktif hingga saat ini. Posyandu dianggap mengalami perpindahan antara budaya tradisional dan modern. Penelitian ini berkontribusi dalam menjelaskan faktor apa saja yang berpengaruh dari budaya bapakisme terhadap dampak individu di organisasi. Hasil dari penelitian ini adalah budaya bapakisme, kualitas informasi, kualitas sistem, kepuasan pengguna mempunyai pengaruh terhadap dampak individual.
\end{abstract}

Kata kunci: budaya organisasi, bapakisme, kualitas informasi, kualitas sistem, kepuasan pengguna, dampak individual

\begin{abstract}
Organizational culture has a role in the quality of information. Not a few organizations that embrace traditional culture (bapakism) in their daily operations. Bapakism is a traditional term issued by the authorities. This becomes interesting when a culture makes work patterns of an organization. In this study shows the father's culture of individuals who represent organizations. The research method was conducted qualitatively and quantitatively. This is done to find out the influence of bapakism culture in Indonesia, especially in organizations close to the community. Posyandu was established in 1984 as a supporting object of research because it is an organization that is still active today. Considered as a substitute for traditional and modern traditions. This research contributes to explain what factors support the culture of bapakism on the influence of individuals in the organization. The results of this research are bapakism culture, information quality, system quality, user satisfaction related to individual influence.
\end{abstract}

Keywords: Organizational culture, bapakism, information quality, system quality, user satisfaction, individual impact 


\section{PENDAHULUAN}

Pemerintah telah lama membentuk organisasi kesehatan yang dikelola oleh warga. Organisasi bidang kesehatan yang disebut Posyandu mempunyai tujuan merangkul dan mengedukasi masyarakat untuk sadar akan pentingnya kesehatan ibu dan anak. Saat ini penerapan budaya pada suatu organisasi perlu adanya pembimbingan khusus yang berguna untuk meningkatkan kinerja anggota. Pentingnya peran dan pengaruh budaya organisasi dapat terlihat dari kualitas informasi yang diperoleh pihak penerima informasi. Informasi tidak hanya dikonsumsi oleh internal organisasi namun juga pihak eksternal, sehingga perlu adanya peningkatan kuliatas dari setiap informasi yang dihasilkan organisasi. Posyandu dipilih menjadi studi kasus dalam penelitian ini karena dianggap sebagai organisasi yang telah lama berdiri. Posyandu telah didirikan dari tahun 1984 di Yogyakarta. Tahun berdirinya posyandu mengindikasikan bahwa budaya organisasi yang terbentuk didalamnya mengandung unsur budaya tradisional di masa itu. Saat dimana budaya tradisional dengan paternalis bapakisme mulai berkembang. Budaya paternalis bapakisme sudah muncul dari masa orde baru pada masa Presiden Suharto.

Pembahasan terkait makna dari budaya organisasi memiliki pemahaman yang berbeda. hal ini tergantung pada bagaimana, dimana dan kapan organisasi itu didirikan. Budaya juga bisa didefinisikan sebagai "keyakinan, nilai, sikap, perilaku, dan praktik [yang dominan] yang merupakan karakteristik dari sekelompok orang" (Warrick, 2017) .Karakteristik yang dibangun dalam organisasi akan mendorong sekelompok individu untuk menciptakan nilai (Gerstner, 2003). Peran pemimpin sangatlah besar dalam membentuk budaya suatu organisasi, selain sebagai panutan, seorang pemimpin juga dituntut agar bisa mengelola internal suatu organisasi. Hal inilah yang baik mampu mengarahkan keberhasilan atau kegagalan organisasi.

Namun, sangat sedikit orang yang paham bagaimana budaya organisasi itu berkerja/ berpengaruh (Alvesson, 2002), dan mengangkat isu tersebut maka diperlukan suatu pengambagan teori pada budaya organisasi terutama di Indonesia. Tidak sedikit suatu lembaga melemah hanya karna kondisi budaya yang diciptakan pada organisasi tersebut, karena kebiasaan yang ditemui di sehari-harinya dapat mengakibatkan sekelompok orang menjadi stress dan tegang. Namun jika tercipta budaya organisasi yang kuat maka akan menimbulkan suasana yang baik saat bekerja. Dalam istilah praktis, budaya organisasi menggambarkan lingkungan di mana orang bekerja dan pengaruhnya terhadap cara mereka berpikir, bertindak, dan pengalaman bekerja (D.D. Warrick, et al., 2016).

Dalam penerapan budaya organisasi biasanya cenderung berbeda, karena visi misi suatu organisasi juga menjadi acuan berjalannya budaya tersebut. Saat organisasi memiliki ciri khas tertentu, maka itu juga yang melekat pada internal organisasi tersebut. Posyandu (Pusat Pelayanan Keluarga Berencana dan Kesehatan Terpadu) adalah kegiatan masyarakat yang berjalan berdasarkan asas kekeluargaan. Mengapa berasas kekeluargaan? Karena organisasi ini diselenggarakan oleh, dari dan untuk warga yang didukung penuh oleh Dinas Kesehatan. Organisasi tersebut dibangun karena kepedulian pemerintah kepada warga sekitar terhadap kesehatan ibu dan anak. Organisasi posyandu rutin diselenggarakan oleh para warga dalam kurun waktu 1 kali dalam sebulan. Sekilas tentang Posyandu adalah kegiatan swadaya di bidang kesehatan yang dilakukan warga yang dipantau oleh seorang pemimpin wilayah tersebut. Ketua wilayah merupakan pihak yang bertanggung jawab dalam rutinitas kegiatan ini, pihak yang dimaksud menjabat sebagai Kepala Desa atau Kepala RW setempat. Organisasi posyandu mempunyai peran penting terhadap penurunan angka kematian bayi (AKB) dan angka kematian ibu hamil. 
Angka kematian balita (AKB) merepresentasikan risiko terjadinya kematian pada fase setelah anak dilahirkan dan sebelum umur 5 tahun. Prestasi dari posyandu dari data Survei Demografi dan Kesehatan Indonesia (SDKI) 2007 menunjukkan angka kematian ibu melahirkan menurun dari 390 kematian per 100.000 kelahiran pada 1990 menjadi 228 kasus pada 2007. Angka kematian bayi menurun dari 70 kematian per 1.000 bayi lahir pada 1986 menjadi 34 pada 2007. Demikian pula angka kematian balita, yang menurun dari 69 kematian per 1.000 kelahiran pada 1993 menjadi 44 pada 2007. Sementara itu, angka kematian balita hanya turun dua, dari 46 kematian per 1.000 kelahiran pada 2000 menjadi hanya 44 pada 2005 (perkembangan paling lambat sejak 2000).

Pada Gambar 1 diestimasikan bahwa dengan adanya posyandu ini mampu menurunkan angka kematian bayi tersebut. Perihal lain jika terjadi resiko pada lokasi tersebut terdapat beberapa faktor yang mempengaruhi antara lain kurangnya edukasi orang tua terkait kesehatan balita, kualitas hidup dan kualiatas lingkungan yang masih rendah.

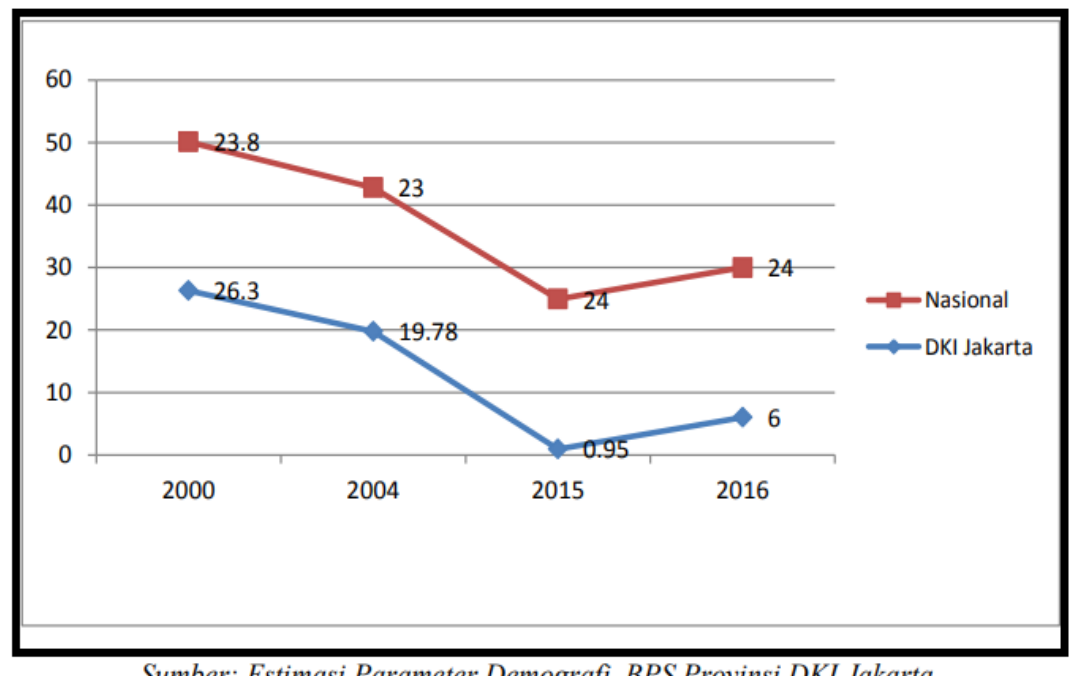

Sumber: Estimasi Parameter Demografi, BPS Provinsi DKI Jakarta

\section{Gambar 1 Estimasi Kematian Balita per-1.000 Kelahiran}

Paternalis bapakisme ini tidak hanya berlaku di Indonesia, beberapa negara di Asia seperti Thailand dan Malaysia juga menjalani paham atau patern bapakisme. Bapakisme juga berjalan di aspek politik, sosial dan ekonomi yang menjadi ciri khas masyarakat di Indonesia. Patern ini merupakan paham yang melambangkan sebuah ketua yang harus dipatuhi dan dilindungi oleh bawahannya. Secara sederhana budaya ini mengharapkan adanya kesempurnaan dalam setiap tindakan yang diperintahkan oleh ketua, dapat dikatakan seperti "asal bapak senang". Sehingga dimungkinkan dengan adanya budaya ini akan mendukung atau malah menghancurkan beberapa pola-pola perusahaan yang secara ilmiah mampu dijalankan di luar negara Indonesia dan beberapa negara di Asia. Jika ditelaah lebih jauh metode-metode hasil penelitian dari suatu negara belum tentu dapat berjalan di negara lain, terlebih lagi negara yang kental faktor budayanya. Beberapa penelitian terdahulu terjadi suatu sentralisasi kekuasaan tingkat tinggi dalam organisasi, dengan otoritas terhadap satu orang yaitu CEO. Ciri kuat dari masyarakat suku Jawa yaitu menerapkan sentralisasi otoritas. (Rademakers, 1998) Paternalisme atau bapakism merupakan yang dilakukan masyarakat dalam organisasi sebagai bentuk kontrol manajemen. 
Tujuan dari penelitian ini yakni agar pemilihan ketua organisasi sosial khususnya Posyandu, diharapkan orang yang mampu mengayomi dan mampu menjadi sosok yang patut untuk dicontoh dalam segala aktifitasnya. Hal ini akan memperlancar proses implementasi kegiatan posyandu yang akhirnya akan menghasilkan informasi dengan berkualitas yang mampu menjadi masukan bagi para pemangku keputusan yang terkait (pihak internal Posyandu atau pihak Dinas Kesehatan).

\section{KAJIAN LITERATUR}

Penelitian ini menggunakan metode survey yang dilakukan kepada kader Posyandu dan beberapa anggota posyandu sebagai pihak yang bertanggung jawab atas kegiatan yang berlangsung. Posyandu menjadi sasaran penelitian karena organisasi ini erat hubungannya dengan kesehatan para warga sekitar. Organisasi yang dekat dengan masyarakat, akan lebih terlihat sifat atau kebiasaan paternalis tradisional yang masih berjalan dalam implementasi kegitan Posyandu. Unsur tersebut berpengaruh pada budaya kerja Posyandu. Pada penelitian terdahulu terdapat faktor yang terkait budaya organisasi, terdapat lima dimensi antara lain individualismekolektivisme, uncertainty avoidance, power distance, maskulinitas/femininitas, dan long-term orientation (Hofstede et al., 1991). Dari lima dimensi tersebut dapat diketahui tinggi rendahnya unsur budaya dalam suatu organisasi.

Masyarakat bersuku Jawa di Indonesia sangat menghormati orang tua atau atasan yang mengarah pada 'Bapak syndrome' (ketua selalu benar dan keputusan akhir hanya atas kehendaknya). Konsep Bapakisme dikaitkan dengan pendekatan manajemen di Indonesia, dimana perintah manajer atau atasan perusahaan harus dilakukan tanpa mempertimbangkan resiko yang dihadapi pelaksana. Perintah baik atau buruk hasur tetap dilaksanakan tanpa ada kelebihan ataupun kekurangan. Hal ini karena seorang Bapak atau ketua (laki-laki/perempuan) harus dihormati dan disegani oleh para pengikutnya. (Rebrová \& Ondrejová, 2012)

Keterkaitan budaya bapakism dengan kinerja perusahaan di Indonesia. Dalam penelitian tersebut dapat diketahui enam dimensi yang berfungsi untuk mengukur tingginya budaya lokal bapakisme disuatu perusahaan. Dimensi tersebut antara lain Pemimpin (Bapak), Sentralisasi, Asal Bapak Senang (ABS), Loyalitas, Rukun, dan Perayaan. (Asfari \& Subriadi, 2017)

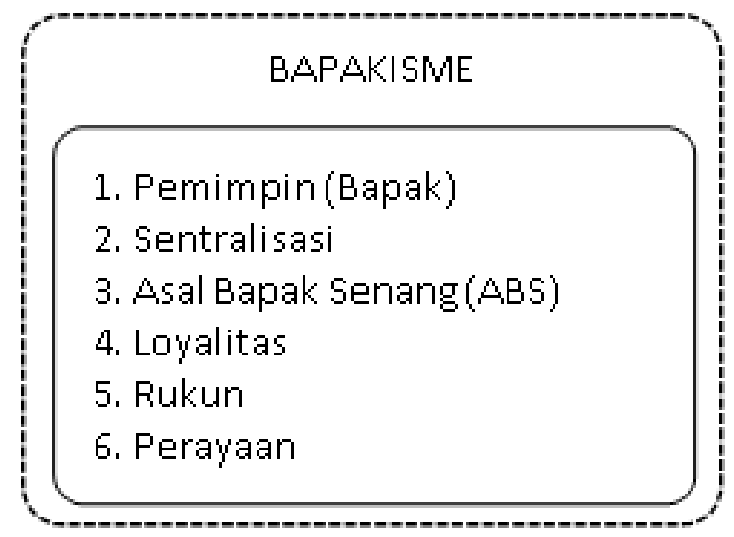

\section{Gambar 2 Variabel Bapakisme (Asfari \& Subriadi, 2017)}

Penelitian terdahulu terdapat pembahasan terkait produktifitas mahasiswa dalam menggunakan e-learning sebagai media pembelajaran mahasiswa. Dalam penelitian ini terdapat beberapa variabel yang mampu mempengaruhi tingginya produktifitas 
mahasiswa antara lain variabel kualitas layanan, kualitas informasi dan kualitas sistem e-learning. Semakin tinggi nilai pada variabel tersbut, maka semakin tinggi pula kepuasaan pengguna. Hal ini berpengaruh signifikan terhadap produktifitas individu mahasiswa pengguna aplikasi tersebut. (Kusumawati, 2003)

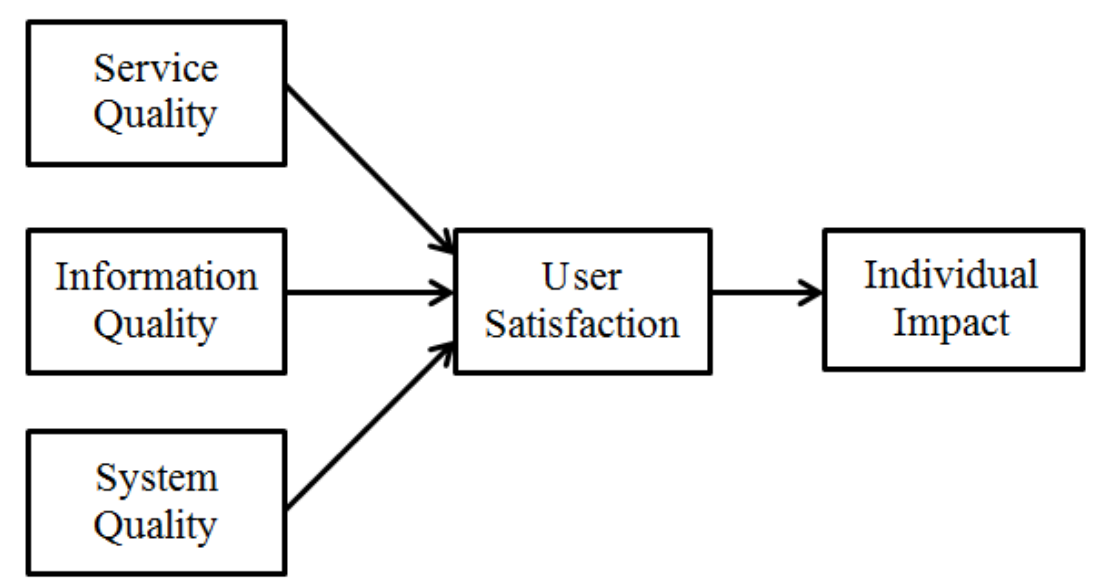

\section{Gambar 3 Model Produktifitas (Kusumawati, 2012)}

Dari beberapa referensi penelitian terdahulu diharapkan peneliti mampu mengambangkan model dan mampu menerapkan model tersebut dalam pembangunan suatu aplikasi sistem informasi KMS. Sehingga diharapkan kendala terkait budaya dan teknologi informasi dapat selaras dan bermanfaat bagi masyarakat.

Harapan dari penelitian ini, faktor-faktor yang mendukung peningkatan kualitas informasi, kualitas sistem dapat dibenahi dengan mempertimbangkan paternalis bapakisme (budaya tradisional). Secara tidak langsung, kualitas informasi dan kualitas sistem dipengaruhi mentalitas seorang pemimpin organisasi. Hal ini berpenagruh pada kepuasan pengguna yang menjadikan kenyamanan yang berdampak pada setiap individu Posyandu. Jika pemimpin organisasi mempunyai sifat seperti dimensi bapakisme (pada Gambar 2) maka para anggota akan menjalankan tugas secara maksimal. Pendataan kesehatan warga haruslah akurat dan terstruktur, data tersebut mempunyai porsi besar dalam pengurangan angka kematian bayi. Jika pemimpin mampu mengerakkan anggota untuk memperbaiki kualitas organisasi, maka akan mempermudah pihak Dinas Kesehatan dalam memproses pengambilan keputusan.

\section{ANALISIS DAN PERANCANGAN}

Pada bagian ini akan membahas tentang metodologi penelitian, kemudian terdapat rangkuman pembahasan sebelumnya menjadi suatu konsep literatur dan disertai juga dengan pembahasannya. Pada bab analisis dan perancangan akan dibahas skema langkah-langkah dalam penelitian. Untuk lebih jelasnya dapat dilihat pada Gambar 5. 


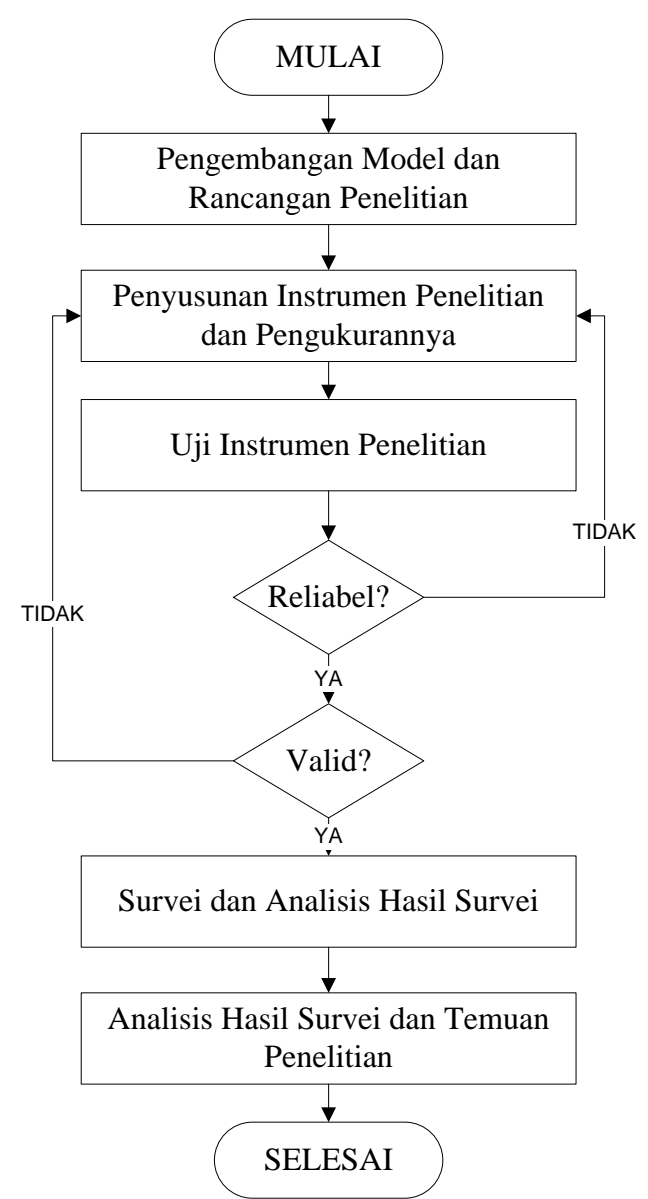

Gambar 4 Tahapan Penelitian

Penelitian ditujukan pada salah satu posyandu yang berada di Kota Surabaya diharapkan data yang terkumpul mendekati validitas yang tinggi. Proses pengujian dan analisis model berupa penelitian kausalitas, deskriptif dan kuantitatif. Penelitian bersifat kausalitas yang dimaksudkan adalah mampu menggambarkan hubungan antar variabel pada model konseptual yang telah dikembangkan, teknik ini disebut regresi. Penelitian ini mengaitkan hubungan antara bapakisme dengan information quality dan system quality, kemudian hubungannya dengan user satisfaction dengan individual impact.

Penelitian ini bersifat deskriptif karena diharapkan melalui pengujian hipotesis mampu memberikan penjelasan fungsi dan dampak dari antar variabel dalam model. Penelitian ini menggunakan pendekatan kuantitatif dimana proses pengukuran berdasarkan fenomena sekitar, yang didukung dengan pencarian data dari beberapa narasumber terkait dengan metode wawancara dan kuisioner. Perhitungan data yang terkumpul akan diuji reliabiltas dan validitasnya menggunakan aplikasi SPSS. Kemudian data sampel tersebut akan diuji keterkaitannya menggunakan GSCA untuk mengetahui nilai antar variabel.

Pada penelitian ini dilakukan pengumpulan data menggunakan teknik wawancara dan survei. Proses wawancara digunakan sebagai bahan dasar pembuatan instrumen pertanyaan kepada responden. Teknik survei digunakan untuk mengolah data yang ada, untuk menguji reliabilitas dan validitas data. Rencana model yang akan dibangun akan mengembangkan model produktifitas dan bapakism. Dengan mempertimbangkan studi yang dilakukan (Iivari, 2005) yang menunjukkan hasil 
bahwa system quality dan information quality merupakan prediktor yang signifikan bagi user satisfaction. Pengumpulan data mengacu pada rencana model kerangka konseptual pada Gambar 5.

Terdapat beberapa penelitian yang membahas budaya organisasi, pada penelitian ini akan menggunakan beberapa parameter yang telah dikaji dari penelitian sebelumnya. Parameter digunakan sebagai variabel pendukung dalam membuat sebuah formulir survey yang akan dibagikan kepada responden yang berperan dalam organisasi tersebut. Pada Tabel 1 tersebut terlihat bahwa tujuh paper membahas pengembangan masing-masing atribut yang dapat digunakan untuk menghitung nilai kontruksi (variabel) secara mendalam. Berikut ini adalah parameter yang telah diteliti pada penelitian sebelumnya.

Tabel 1 Studi Yang Membahas Parameter Penilaian Budaya Organisasi

\begin{tabular}{|c|c|c|c|}
\hline Studi Empiris & Konteks & $\begin{array}{l}\text { Konstruksi yang } \\
\text { Digunakan }\end{array}$ & Sub-dimensi \\
\hline $\begin{array}{l}\text { (Asfari \& } \\
\text { Subriadi, 2017) }\end{array}$ & $\begin{array}{l}\text { Kematangan } \\
\text { Manajemen } \\
\text { Portofolio TI }\end{array}$ & Bapakism & $\begin{array}{l}\text { Pemimpin (Bapak) } \\
\text { Sentralisasi } \\
\text { Asal Bapak Senang (ABS) } \\
\text { Loyalitas } \\
\text { Rukun } \\
\text { Perayaan }\end{array}$ \\
\hline \multirow{2}{*}{$\begin{array}{l}\text { (Xu, Benbasat, \& } \\
\text { Cenfetelli, 2013) }\end{array}$} & \multirow{2}{*}{$\begin{array}{l}\text { Consumer } \\
\text { websites }\end{array}$} & $\begin{array}{l}\text { Information } \\
\text { Quality } \\
\text { (1 } 1^{\text {st }} \text { order) }\end{array}$ & $\begin{array}{l}\text { Completeness } \\
\text { Accuracy } \\
\text { Format } \\
\text { Currency }\end{array}$ \\
\hline & & $\begin{array}{l}\text { System Quality } \\
\text { (1t } \text { order) }\end{array}$ & $\begin{array}{l}\text { Reliability } \\
\text { Flexibility } \\
\text { Accessibility } \\
\text { Timeliness } \\
\end{array}$ \\
\hline \multirow{3}{*}{$\begin{array}{l}\text { (Yi, Yoon, Davis, } \\
\text { \& Lee, 2013) } \\
\text { (Zheng, Zhao, \& } \\
\text { Stylianou, 2013) }\end{array}$} & \multirow{3}{*}{$\begin{array}{l}\text { Websites with } \\
\text { health } \\
\text { information } \\
\text { Virtual } \\
\text { Community }\end{array}$} & $\begin{array}{l}\text { Information } \\
\text { Quality } \\
\left.\text { (1 } 1^{\text {st }} \text { order }\right)\end{array}$ & $\begin{array}{l}\text { Currency } \\
\text { Accuracy } \\
\text { Relevancy } \\
\text { Usefulness } \\
\text { Completeness } \\
\end{array}$ \\
\hline & & $\begin{array}{l}\text { Information } \\
\text { Quality } \\
\left(2^{\text {nd }} \text { order }\right)\end{array}$ & $\begin{array}{l}\text { Reliability } \\
\text { Objectivity } \\
\text { Value-added } \\
\text { Timeliness } \\
\text { Richness } \\
\text { Format } \\
\end{array}$ \\
\hline & & $\begin{array}{l}\text { System Quality } \\
\left(2^{\text {nd }} \text { order }\right)\end{array}$ & $\begin{array}{l}\text { Navigation } \\
\text { Accessibility } \\
\text { Appearance } \\
\text { Security } \\
\text { Interactivity }\end{array}$ \\
\hline \multirow[t]{2}{*}{$\begin{array}{l}\text { (Forsgren, Clay, } \\
\text { Wang, } \quad \& \\
\text { Durcikova, 2016) }\end{array}$} & \multirow{2}{*}{$\begin{array}{l}\text { IS } \\
\text { characteristics } \\
\text { important in } \\
\text { system } \\
\text { administration }\end{array}$} & $\begin{array}{l}\text { Information } \\
\text { Quality } \\
\left(2^{\text {nd }} \text { order }\right)\end{array}$ & $\begin{array}{l}\text { Accuracy } \\
\text { Completeness } \\
\text { Currency } \\
\text { Format }\end{array}$ \\
\hline & & $\begin{array}{l}\text { System Quality } \\
\left(2^{\text {nd }} \text { order }\right)\end{array}$ & $\begin{array}{l}\text { Accessibility } \\
\text { Flexibility } \\
\text { Integration }\end{array}$ \\
\hline
\end{tabular}




\begin{tabular}{|l|l|l|l|}
\hline Studi Empiris & Konteks & $\begin{array}{c}\text { Konstruksi yang } \\
\text { Digunakan }\end{array}$ & \multicolumn{1}{c|}{ Sub-dimensi } \\
\hline & & & $\begin{array}{l}\text { Reliability } \\
\text { Timeliness }\end{array}$ \\
\hline $\begin{array}{l}\text { (Wu \& Wang, } \\
\text { 2006) }\end{array}$ & $\begin{array}{l}\text { Knowledge } \\
\text { Management } \\
\text { System (KMS) }\end{array}$ & User satisfaction & $\begin{array}{l}\text { Adequate } \\
\text { Efficiency } \\
\text { Effectiveness } \\
\text { Overall Satisfaction }\end{array}$ \\
\hline (Davis, 1989) & & Individual Impact & $\begin{array}{l}\text { Task performance } \\
\text { Job performance } \\
\text { Productivity } \\
\end{array}$ \\
& & $\begin{array}{l}\text { Job effectiveness } \\
\text { Job simplification } \\
\text { Usefulness }\end{array}$ \\
\hline \hline
\end{tabular}

Penelitian ini mempunyai tinjauan literatur untuk mencari variabel apa saja yang berkaitan antara budaya organisasi dan pengaruh individu. Model dinyatakan valid, maka dilakukan simulasi awal berdasarkan kondisi saat ini kemudian dianalisa. Hasil analisa akan menunjukkan variabel yang berpengaruh signifikan terhadap tujuan yang ingin dicapai. Dari variabel tersebut maka akan dilakukan simulasi skenario kebijakan yang tepat.

\subsection{PENGUMPULAN DATA}

Pengumpulan data menggunakan metode survey dengan rincian hasil dari kuisioner yang telah disebar, ditemukan 5 kuisioner yang tidak layak dan tidak kembali. Sehingga jumlah kuisioner yang layak untuk diolah sebanyak 42 kuisioner. Pengujian instrumen penelitian selanjutnya dilakukan dengan uji reliabilitas, uji validitas menggunakan perangkat lunak Statistical Package for the Social Sciences (SPSS). Pada hasil penelitian ini telah dinyatakan lolos uji validitas dan reliabilitas jika nilai indicator dan signifikansi memenuhi syarat yang ditentukan. Untuk uji validitas instrument kuisioner dikatakan valid apabila bilangan koefisien korelasi antara nilai suatu indikator dengan total nilai seluruh indikator adalah $>0.3$ atau nilai signifikansi ( $p$-value) $<0.05$ (Solimun, 2002). Data survey yang reliabel jika nilai Cronbach Alpha semakin dekat dengan nilai 1 , hal ini disimpulkan bahwa item-item pernyataan dalam instrumen kuisioner semakin reliabel (Ghozali, 2006).

Proses selanjutnya yakni menilai keterkaitan antar variabel yang telah dideklarasikan sebelumnya, aplikasi online yang mendukung bernama Generalized Structured Component Analysis (GSCA). Perangka lunak ini dipilih karena dapat mengolah data yang bersifat reflektif dan formatif dalam waktu yang bersamaan (Choi, Yang, Tenenhaus, \& Hwang, 2018).

Terdapat lima hipotesis yang dilakukan pada penelitian ini, antara lain:

- H1: Budaya bapakisme mempengaruhi kualitas informasi (information quality) dalam sebuah organisasi

- H2: Budaya bapakisme mempengaruhi kualitas sistem (system quality) yang berjalan di sebuah organisasi.

- H3: Kualitas informasi (information quality) mempunyai pengaruh terhadap kepuasan pengguna (user satisfaction).

- H4: Kualitas sistem pada sebuah organisasi juga mempunyai pengaruh terhadap kepuasan pengguna (user satisfaction). 
Pengaruh Budaya Organisasi Pada Kualitas Informasi Yang Berdampak Pada Individu Organisasi

- H5: Kepuasan pengguna (user satisfaction) mempunyai pengaruh terhadap dampak individu (individual impact) suatu organisasi.

\subsection{ANALISIS INFERENSIAL}

Data yang didapat dari penyebaran dan pengolahan kuisioner dimasukkan dalam aplikasi online GeSCA.

Tabel 2 Hasil Measurement of Fit Structural Model

\begin{tabular}{|c|c|}
\hline \multicolumn{2}{|c|}{ Model Fit } \\
\hline FIT & 0.408 \\
\hline AFIT & 0.383 \\
\hline NPAR & 42 \\
\hline
\end{tabular}

Berdasarkan output dari aplikasi GeSCA Identifikasi Goodness of FIT pada Tabel 2 mendapatkan nilai FIT $=0.403$. Penjelasan dari nilai FIT yakni menunjukkan varian total dari semua variabel yang dapat dijelaskan oleh model tertentu. Nilai FIT idealnya berkisar dari 0 sampai 1 . Sehingga model yang terbentuk, dapat menjelaskan variabel yang ada sebesar 0.408 . Keragaman variabel yang terdiri dari Budaya Bapakisme, Service Quality, Information Quality, System Quality, Users Satisfaction, serta Individual Impact dapat dijelaskan oleh model sebesar 40,8\% . Sisanya 59,2\% dapat dijelaskan oleh variabel lain.

Berdasarkan output dari aplikasi GeSCA dapat diidentifikasi bahwa pada Tabel 2 terlihat Goodness of FIT didapatkan nilai AFIT sebesar 0.383. Didalam model ini terdapat multi variabel yang mempengaruhi individual impact, oleh karena itu sebaiknya melakukan interpretasi ketepatan model dengan FIT yang sudah terkoreksi (AFIT). Dilihat dari nilai AFIT, Keragaman variabel yang terdiri dari Service Quality, Information Quality, System Quality, Users Satisfaction, serta Individual Impact dapat dijelaskan oleh model sebesar $38.3 \%$. Sisanya $61.7 \%$ dapat dijelaskan oleh variabel lain.

Berdasarkan output GeSCA dari identifikasi Goodness of FIT pada tabel diatas, didapatkan nilai NPAR $=42$. Number of Free Parameters Eestimated (NPAR) menunjukan banyaknya parameter bebas yang digunakan dalam perhitungan alat bantu GeSCA, termasuk weights, loadings, and path coefficients.

Pengujian Hipotesis dalam penelitian ini dapat dianalisis dari nilai yang ditunjukkan oleh output GeSCA yang berupa Path Coefficients pada measures of fit model struktural. Pada hasil tersebut terdapat nilai estimate, standard error, dan critical ratio yang dapat dikaji lebih lanjut, karena Path Coefficients menggambarkan hubungan setiap variabel. 
Table 1 Path Coefficients

\begin{tabular}{|c|c|c|c|}
\hline \multicolumn{4}{|c|}{ Path Coefficients } \\
\hline & Estimate & SE & CR \\
\hline Bapakisme->Information_Quality & 0.513 & 0.132 & $3.9^{*}$ \\
\hline Bapakisme->System_Quality & 0.621 & 0.102 & $6.12^{*}$ \\
\hline $\begin{array}{c}\text { Information_Quality- } \\
\text { >User_Satisfaction }\end{array}$ & -0.439 & 0.060 & $7.26^{*}$ \\
\hline $\begin{array}{c}\text { System_Quality- } \\
\text { >User_Satisfaction }\end{array}$ & 0.146 & 0.019 & $7.5^{*}$ \\
\hline $\begin{array}{c}\text { User_Satisfaction- } \\
\text { >Individual_Impact }\end{array}$ & 0.194 & 0.053 & $3.69^{*}$ \\
\hline \hline
\end{tabular}

$\mathrm{CR}^{*}=$ significant at .05 level

Nilai Path Coefficients untuk hubungan antar variabel dalam model, yang ditunjukkan oleh Tabel 3, bila digambarkan ke dalam konstruk variabel pada model empiris penelitian ini dapat terlihat seperti Gambar 6 di bawah ini.

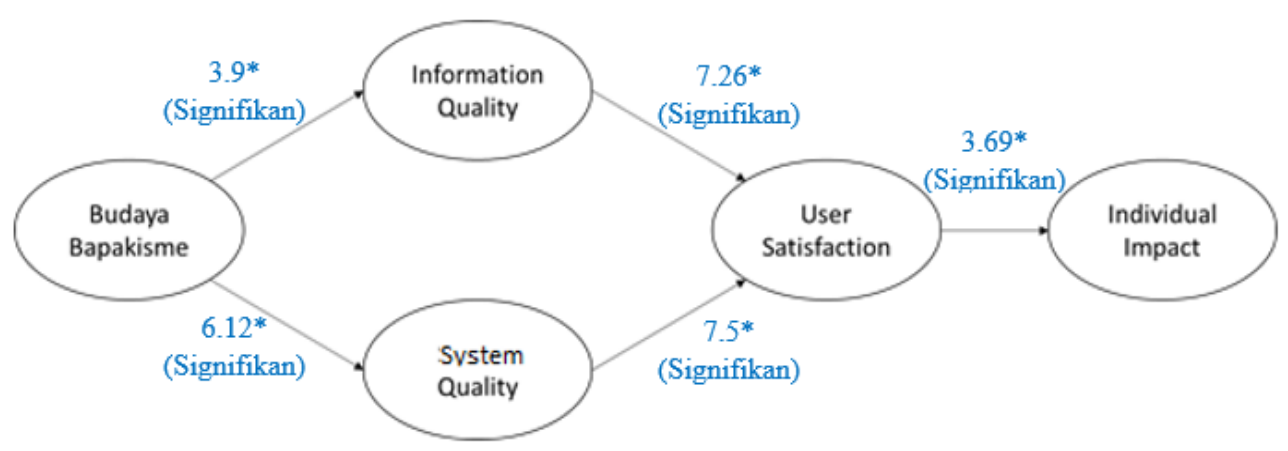

Gambar 5 Hasil Path Coefficient

Nilai Signifikansi dapat diketahui dari nilai critical ratio yang terlihat pada Tabel 3. Terdapat lima critical ratio dengan tanda bintang $(*)$, hal ini menandakan bahwa hasil dari pengolahan data antara variabel yang terkait saling mempengaruhi dan menghasilkan nilai positif signifikan. Hasil hipotesis dari yang terlihat setelah menjalankan aplikasi GeSCA bahwa, hipotesis $1=$ diterima, hipotesis 2 = diterima, hipotesis 3 = diterima, hipotesis $4=$ diterima, hipotesis $5=$ diterima.

\section{KESIMPULAN}

Hasil dari tinjauan literature mengenai kaitan antara budaya organisasi (bapakisme) dengan pengaruh individual berpengaruh signifikan positif. Hal ini mengindikasikan bahwa budaya bapakisme mempunyai pengaruh dalam pengelolaan organisasi yang mempunyai dampak pada individu organisasi. Pada kajian teori terlihat bahwa budaya organisasi mempunyai kaitan dengan terbentuknya kualitas informasi dan kualitas sistem. Banyak penelitian yang mengembangkan dimensi pendukung guna mengukur nilai kualitas informasi dan kualitas sistem. Pada pengukuran kualitas informasi terdapat atribut yang dapat dipertimbangkan untuk ditambahkan yakni relevancy, usefulness, value-added, dan richness. Dengan atribut tersebut dapat mengoptimalkan kualitas informasi di suatu organisasi. 
Jadi tujuan yang ingin diketahui melalui tinjauan literatur yang telah dibahas diatas. Perlu untuk mengetahui metode penelitian apa yang akan dipakai, lakukan tinjauan lapangan terhadap beberapa responden. Sehingga dampak budaya organisasi (bapakisme) pada pengaruh individual dapat diketahui secara jelas.

\section{UCAPAN TERIMA KASIH}

Dengan hormat, sehubungan dengan sudah terbitnya jurnal ini pada Jurnal IMIND, peneliti mengucapkan terima kasih atas bantuan tim yang telah bersedia mendukung dan menyampaikan sumbangan pemikiran dalam pembenahan dan penyempurnaan naskah jurnal yang berjudul "Pengaruh Budaya Organisasi terhadap Kualitas Informasi Berdampak Pada Individu Organisasi" yang telah masuk pada dewan redaksi. Kami ucapkan terima kasih kepada pihak yang telah mendukung dan membiayai proses pembuatan penelitian yakni Direktorat Riset dan Pengabdian Masyarakat, Direktorat Jenderal Penguatan Riset dan Pengembangan, Kementrian Riset, Teknologi, dan Perguruan Tinggi.

\section{DAFTAR RUJUKAN}

Alvesson, M. (2002). Understanding Organizational Culture.

Asfari, U., \& Subriadi, A. P. (2017). Pengaruh Budaya Bapakism Dan Kematangan Manajemen Portofolio Teknologi Informasi (Mpti) Terhadap Kinerja Perusahan. Sisfo, 05(04). https://doi.org/10.24089/j.sisfo.2015.09.001

Choi, J. Y., Yang, S., Tenenhaus, A., \& Hwang, H. (2018). Three-way generalized structured component analysis. Springer Proceedings in Mathematics and Statistics, 233(February), 195-209. https://doi.org/10.1007/978-3-319-77249-3_17

Davis, F. D. (1989). Perceived Usefulness, Perceived Ease of Use, and User Acceptance of Information Technology. MIS Quarterly, 13(3), 319. https://doi.org/10.2307/249008

Forsgren, N., Clay, P. F., Wang, X., \& Durcikova, A. (2016). The integrated user satisfaction model: Assessing information quality and system quality as second-order constructs in system administration. Communications of the Association for Information Systems, 38(1), 803-839. https://doi.org/10.17705/1CAIS.03839

Gerstner, L. V. (2003). Who Says Elephants Can't Dance? Harvard Business Review, 81(1), $22 . \quad$ Retrieved from http://search.ebscohost.com/login.aspx?direct=true\&db=bth\&AN=9024459\&site $=$ eh ost-live\&scope=site

Ghozali, I. (2006). Aplikasi Analisis Multivariate dengan Program SPSS.

Hofstede et al. (1991). Cultures and Organizations. Cultures and Organizations, 561. https://doi.org/10.1007/s11569-007-0005-8

Iivari, J. (2005). An empirical test of the DeLone-McLean model of information system success. ACM SIGMIS Database, 36(2), 8-27. https://doi.org/10.1145/1066149.1066152 
Kusumawati, A. (2003). Analisis Kualitas Sistem Informasi Terhadap Peningkatan Produktivitas Dan Pengetahuan Mahasiswa Sebagai Pengguna Media Pembelajaran Berbasis E-Learning. Teknik POMITS, 1-8.

Rademakers, M. F. L. (1998). Market Organization in Indonesia: Javanese and Chinese Family Business in the Jamu Industry. Organization Studies, 19(6), 10051027. https://doi.org/10.1177/017084069801900605

Rebrová, S., \& Ondrejová, Z. (2012). Indonesian Business Etiquette, Language and Culture. 397-402.

Warrick, D. D. (2017). What leaders need to know about organizational culture. Business Horizons, 60(3), 395-404. https://doi.org/10.1016/j.bushor.2017.01.011

Wu, J. H., \& Wang, Y. M. (2006). Measuring KMS success: A respecification of the DeLone and McLean's model. Information and Management, 43(6), 728-739. https://doi.org/10.1016/j.im.2006.05.002

Xu, D. J., Benbasat, I., \& Cenfetelli, R. T. (2013). Integrating Service Quality with System and Information Quality: An Empirical Test in the E-Service Context. MIS Quarterly, 37, 777-794. https://doi.org/10.25300/MISQ/2013/37.3.05

Yi, M. Y., Yoon, J. J., Davis, J. M., \& Lee, T. (2013). Untangling the antecedents of initial trust in Web-based health information: The roles of argument quality, source expertise, and user perceptions of information quality and risk. Decision Support Systems, 55(1), 284-295. https://doi.org/10.1016/j.dss.2013.01.029

Zheng, Y., Zhao, K., \& Stylianou, A. (2013). The impacts of information quality and system quality on users' continuance intention in information-exchange virtual communities: An empirical investigation. Decision Support Systems, 56(1), 513-524. https://doi.org/10.1016/j.dss.2012.11.008 